\title{
Research Engagement of Foreign Language Teachers among Select Higher Education Institutions in Malaysia
}

\author{
Sanil S Hishan ${ }^{1}$, Suresh Ramakrishnan ${ }^{1}$,Nur Naha binti Abu Mansor ${ }^{1}$ \\ ${ }^{1}$ Azman Hashim International Business School (AHIBS), Universiti Teknologi Malaysia, \\ Malaysia. Corresponding Author: hishanssanil@gmail.com
}

\begin{abstract}
This paper aims to add to established awareness on the extent of research capacity, theoretical ideas, and views on the challenges to their study involvement in Malaysia's select universities. It used a hybrid system of concise quantitative and qualitative projects for 62 foreign language students. Data gathering methodologies such as questionnaires, individual and group interviews were used. Results from the quantitative portion of the paper showed that international teachers displayed a modest degree of research ability while they hold optimistic views on the principles of study as a method to offer answers to educational challenges transcending teacher subject awareness, pedagogical and instructional abilities, and optimistic student learning outcomes. Similarly, qualitative findings found that the barriers to international teachers ' participation in research are embodied in lack of time to do work and lack of study writing skills. Moreover, networking incentive and career growth are driving factors for international teachers in Malaysia. The research poses implications on instructional management among curriculum designers, scholars, and school administrators among universities in Malaysia to improve academic culture and professional development opportunities among international teachers in terms of research capability and participation.
\end{abstract}

Keywords - Research Capabilities, Foreign Teachers, Knowledge generation, Research, Educational Management, Research Productivity

\section{INTRODUCTION}

Research plays a critical role in nation-wealth creation. In today's information, work is an significant predictor of global innovation index that determines a country's capacity to produce new knowledge and technology for human use and survival. Development is impossible without quality work that leads to advancing the new frontiers of awareness and ways of thought and adaptation in present environmental systems. Consequently, the productivity of countries around the world is better calculated by producing research dissemination, patents and information (Larsen et al, 2010).

Science is intertwined with national development. Universities as the center of academic growth and technological advancement are required to perform their responsibilities to educate and create high-graduates, academics and experts who, by fostering global progress, will serve as a force for change. Based on extensive literature, Jones \& Hoyler (2012) suggests that the emergence of global ranking is a reflection of scalar change in higher education geopolitics and geo-in prioritizing research and growth. It is widely agreed that encouraging literacy, teaching, skills growth, and awareness creation among individuals are the primary goals of education. These educational thrusts are rooted in the roles of the world's higher education institutions, especially Malaysia's universities where teachers are supposed to be the prime movers of work beginning in

(C) AesthetixMS 2020. This Open Access article is published under a Creative Commons Attribution Non-Commercial 4.0 International License (http://creativecommons.org/licenses/by-nc/4.0/), which permits non-commercial re-use, distribution, and reproduction in any medium, provided the original work is properly cited. For citation use the DOI. For commercial re-use, please contact editor@rupkatha.com. 
college classrooms that eventually translated into the course syllabi they teach. Therefore, the teaching of potential professionals relies on the consistency of the program, focusing on the positions and strengths of college teachers and professors.

\section{Teacher Professionalism and Training}

Teachers are the foundation of the school system and sources of good instruction. International teachers identify part of education experience in Malaysia in the context of study interaction. Fullan (2013) affirms that one of the main reasons for teachers to manifest progress and ingenuity is their strong and constructive participation in science. Education among teachers is also a must and an important part of teaching growth as an evidence- discipline (Furlong \& Salidbury, 2005; Chow, Chu, Taveras, \& Lee, 2015). Therefore, teachers ' active engagement and participation in taking the leading role in conducting research in Malaysia would be a very significant approach to introducing creativity to teaching and successful facilitation of professional growth.

\section{Review on the EFL Teacher Research Engagement, and Motivation}

EFL instructor work is gaining global recognition and acceptability (Al-Maamari, Al-Aamri, Khammash \& Al-Wahaibi (2017). From a South American perspective, Burns \& Westmacott (2018) stated that Chilean universities need to promote the professional growth of EFL teachers, capturing their transition from becoming a teacher in the classroom to being teacher researchers. For North American context, del Rosario (2018) explored the feasibility, encouragement and value of research perceptions and challenges among professors and foreign language lectures in Mexico. They reported high effectiveness among participants, but minimal research participation indicated likelihood that language teachers overestimated their testing abilities. Keuk (2015) in South East Asia, Cambodia, discovered that EFL teachers keep vague and uncertain science definitions leading to their work participation difficulties. Therefore, Cambodia calls for an effort to reconceptualize ELT teacher participation. Kiathkheeree (2014) also analyzed an EFL Thailand university's research culture reported that EFL teachers research engagement is a result of external and internal influencing factors showing time limitations, insufficient resources, and restricted institutional support are the main factors affecting research engagement. It was proposed that EFL teachers require more support and incentive to participate in work to develop their teaching skill. All the studies discussed anchored their advice on effective study management strategies with a emphasis on improving foreign language teachers ' study involvement through an efficient and sustainable faculty development plan. Faculty leaders, one of the most critical components in higher education institutions, have a leading role in R\&D. Therefore, University administration requires a good support system to allow them to achieve their ultimate flourishing career.

\section{Challenges in Conducting Research}

Bai's new report (2018) exploring the confidence of language teachers in research from two higher education institutions in Malaysia showed that teachers have differing work perspectives, institutional environment and culture, and work management processes. Language teachers were recommended to be more interested in work by a need-faculty recruitment plan. Similarly, Borg \& Lui (2013a, 2014b) reiterated their analysis using mixed testing approaches to investigate the essence of the involvement of language teachers in testing in Malaysia. It was observed that there is unproductive linearity and assumptions between study and classroom activities. Asking to encourage intense teacher study participation, which is beneficial to the growth of English teachers. $\mathrm{Xu}$ (2014) also stated that EFL research teachers ' commitment and motivations are 
influenced by their research policy experiences. Promoting EFL teachers' study ability and participation needs constructive contributions from university administrators and mentors.

Work is due to two main influences in higher education systems. Second, work strengthens instruction, and second study suggests academic reputation (Alhija \& Majdob, 2017). The imminent aspect that hinders Malaysia's teacher-flourishing is due to culture (Chow, Chu, Tavares \& Lee, 2015). Typically, teachers are not yet professionally educated and dedicated to study as part of their educational practice. Bergner Boles and Troen's (2005) report indicated teachers were unaware of the function and scope of education science. We find work very difficult and complex, as only specialists and university academics can do. Only those service teachers who concentrate on their position as researcher find it difficult to bring their work into dissemination and publication (Biruk, 2013; Vazques, 2017, Norashmah \& Chia, 2016, Ellis \& Loghland, 2016). Therefore, if teachers are unable to conduct and participate in testing, they will be unable to perform their duties successfully (Ulla, 2016). Consequently, it inevitably impacts their career growth as teachers understand unfavorable mentality towards work (Borg, 2014). In comparison, teachers with optimistic attitudes on work in their professional growth encourage new experiences in their professional development.

Generally, the findings discussed offered analytical guidance on teachers' work challenges. However, the studies reported did not discuss teachers ' assistance in conducting research. Moreover, few studies have attempted to examine international teachers' problems and difficulties about their study capabilities in Malaysia. The present thesis would resolve the literature gap and have significant lessons for university education management.

\section{Context and Research Gap}

English is taught and studied internationally (Wang, 2007). The success of language teaching from basic to higher education levels attracted attention (Bai \& Hudson, 2011). Although most of the literature reviewed and edited discussed study engagement as an effective medium for professional growth among teachers in different countries (Mehrani, 2015; Mehrani \& Behzadnia, 2013, del Roario 2018, Borg \& Lui, 2013a, 2014b; Bai, 2018; Xu, 2014; Burns \& Westmacott, 2018; Keuk, 2015; Kiathkheeree, 2014). There is a strong lack of research literature venturing on basic teaching abilities, instructor capacity, and study engagement. Nonetheless, literature looking for this topic revealed a very small number of articles focusing on including international teachers in work (Mehrani, 2015). Such investigation, though, is a valuable framework for clinicians on how to tackle such a void in the actual world. Similarly, this paper tried to fill the literature void by disclosing Chinese universities ' Foregoing teachers ' study ability. This paper suggests that improving the work environment through constructive and efficient educational management would create opportunities to improve the work potential of international teachers in Malaysia to lead the dissemination of research results rooted in information sharing. With limited studies conducted among universities in Malaysia on international teachers ' research capabilities, this study hopes to fill the literature gap that will help resolve teachers ' research ability enhancement needs.

\section{OBJECTIVES OF THE STUDY}

This report examined international teachers' research capabilities. It tried to address the following research inquiries: (1) what is the research potential of international teachers?(2) How do international teachers view research? (3) What are international teachers ' views on the challenges to their research k engagement? 


\section{MATERIALS AND METHODS}

\section{Research Design}

This paper canters its investigation on the research capabilities of foreign teachers in Malaysia using a mixed method of descriptive quantitative and qualitative designs. This type of design is described by Schoonenboom \& Johnson (2017) as a way to combine qualitative and quantitative data which strengthens the study's' findings because of its depth and breadth of corroboration and analysis.

\section{Research Participants and Gathering Procedure}

Anchored on the ethical research consideration, personal information and details given by the participants were confidentially treated. Prior to the selection and identification and selection of participants, a written request was sent and approved by the authorities. Data privacy agreement form was also filled out by the respondents. The proper selection of participants was made through the assistance of the school heads. As such, a total of 62 foreign language teachers with inform consent participated in the study. In like manner, to validate the quantitative data, interviews were conducted to a total of 10 respondents. Hence, triangulation was employed in order to obtain truthful data.

Results of the analysis of the personal profile variables of the respondents showed Majority of the respondents are female, have 5-30 years to teaching experience, most of them have advanced education while least number of the respondents did not have advance education. Nationalities of the foreign language teachers were not mentioned to observe ethical race characteristics.

\section{Research Instruments}

Measure of Research Capability: To measure the research capability of the foreign teachers towards research was adapted from Meerah, Osman, Zakarina, Ikhsan et al (2012) which is the measure of research skills. The instrument is a diagnostic measure to identify the research competencies of teachers with 13 statements. The instrument is a self-assessed tool with a 5point likert scale with descriptive interpretation and ranges: Highly Capable ${ }^{a}$ (4.20-5.00); Very Capable $^{\mathbf{b}}$ (3.40-4.19); Moderately Capable $^{\mathbf{c}}$ (2.60-3.39); Fairly Capable ${ }^{\mathbf{d}}$ (1.80-2.59); Not Capable ${ }^{\mathrm{e}}(1.00-1.79)$.

Measure of Conceptions on the Values of Research: The measure the level of foreign teachers' research conceptions, the instrument by Biruk (2013) and O'Connor et al (2006) was adapted, modified, and utilized. The statement has 8 items answered with a 5-point likert scale with the following descriptive interpretations and scale ranges: Strongly Agree ${ }^{\mathrm{a}}(4.20-$ 5.00); Agree ${ }^{\mathrm{b}}$ (3.40-4.19); Undecided c (2.60-3.39); Disagree ${ }^{\mathrm{d}}$ (1.80-2.59); Strongly Disagree ${ }^{\mathrm{e}}$ (1.00-1.79). Responses were properly tabulated and subjected to appropriate statistical test.

Socio-Demographic Profile Form: The data on the profile variables of the respondents was elicited using the socio-demographic profile form which identified the gender, years of teaching experience, and level of education.

Qualitative Data: Upon completion of the survey, 20 foreign teachers were selected for the individual or group interviews which were conducted in varying days since only those who have vacant periods were invited for the interviews. Hence, the conduct of the interviews was schedule based on the availability of the respondents to observe non-class disruption. 


\section{Data Analysis}

For the quantitative component of the study, data gathered were tabulated and properly subjected to statistical computation and analysis using descriptive statistical tool such as mean, weighted mean and standard deviation. The mean as measure of central tendency was used to get the sum of all the observations divided by the number of observations. Meanwhile, standard deviation reflected the variability of dispersion of the data. For qualitative component of the study, the data were transcribed and subject to content analysis highlighting the emerging themes from the interviews. The narratives of the participants were coded and analysed to ascertain the themes which emerged gradually.

\section{RESULTS AND DISCUSSION}

\section{Foreign Teachers' Level of Research Capability}

The findings from the surveyed questionnaire to answer research question number 1 on how do the foreign teachers' manifest their level capability in doing research is presented. To provide answer to the question, mean and standard deviation were used. Table 1 showcases a moderate level of research capability of the foreign teachers with the grand mean of 2.65. Implying that they have not yet develop the sufficient knowledge to do research. The adequate knowledge of teachers to conduct research is essential in the global educational landscape. Table's 1 results are in corroboration with previous findings (Morales, 2016; Shariatmadari \& Mahdi, 2012) that teachers are not yet fully equipped with the necessary and basic skills in conducting research.

Table 1. Foreign Teachers' Research Capability to Conduct Research

\begin{tabular}{|c|c|c|c|}
\hline Research Capability & $\begin{array}{l}\text { Mean } \\
(n=62)\end{array}$ & S.D. & Interpretation \\
\hline Ability to plan a research & 2.56 & 0.802 & Moderately Capable \\
\hline Developing a research question & 2.62 & 0.706 & Moderately Capable \\
\hline Searching for research gaps & 3.20 & 1.073 & Moderately Capable \\
\hline Doing literature review & 2.51 & 0.804 & Fairly Capable \\
\hline Design experimental study & 2.20 & 0.812 & Fairly Capable \\
\hline Selecting a proper instrument & 2.46 & 1.302 & Moderately Capable \\
\hline Developing instrument & 2.27 & 1.243 & Fairly Capable \\
\hline Collecting survey data & 2.37 & 1.089 & Moderately Capable \\
\hline Writing research abstracts & 2.90 & 0.670 & Moderately Capable \\
\hline Preparing a manuscript for publication & 2.54 & 1.140 & Fairly Capable \\
\hline Selecting an appropriate research method & 2.33 & 1.070 & Fairly Capable \\
\hline Choosing an appropriate method analysis of data & 3.41 & 0.615 & Moderately Capable \\
\hline Interpreting the result of a research study & 2.48 & 0.740 & Fairly Capable \\
\hline Grand Mean & 2.61 & & Moderately Capable \\
\hline
\end{tabular}

Legend: Highly Capable ${ }^{a}$ (4.20-5.0o); Very Capable ${ }^{b}$ (3.40-4.19); Moderately Capable (2.60-3.39); Fairly Capable ${ }^{d}$ (1.80-2.59); Not Capable ${ }^{e}(1.00-1.79)$

A closer glance at the data, the respondents manifested a moderate level of research capability on choosing appropriate method of analysis; identifying research gaps; writing research abstracts; 
and developing research question. In like manner, the respondents manifested insufficient or fairly capable research skill on planning a research, preparing manuscript for publication, doing literature review, interrupting results, selection of appropriate research tool, data gathering, using appropriate research method, developing instrument and the least is design experimental study. Having these findings, it provided a clear implication for the reorientation of the concept of research among the teachers which is attributed to the lack of effective guidance and direction for the correct substance and form of research, hence arriving at a meaningful and relevant contribution in the field of research education.

The findings on the moderate level of foreign language teachers' research capability in the universities of Malaysia is backed up with several studies (Xiao, 2002; Gao, 2006; Dai \& Zhang, 2004). It was confirmed that there is a limited level of research engagement of Teaching English as a Foreign Language (TEFL) teachers as evidenced by their few research projects and publications to international referred journals (Yang et al, 2001; Borg, 2003, \& Huang, 2006).

With the identified level of research capability of foreign teachers, it indicates that there is a need for areas of intensive professional development focusing on the research process, research design, problem and gaps identification, literature searches, and research report writing. These components are important for the teachers to develop since research is an integrative skill. The findings are consistent with Burns (2010) confirming that teachers need intensive trainings on research for them to develop their skill. Also, the difficulties of teachers in conducting research has been confirmed by studies (Vec \& Rupar, 2015; Vazquez, 2017, Ulla, 2018; Morales, 2016a,\& $2017 \mathrm{~b}$ ). Thus, significant reforms in educational management focusing on research skills of teachers must be initiated.

\section{Foreign Teachers' Conceptions of Research}

Providing a ground on the concepts of foreign teachers towards research is an interesting topic on inquiry. This provided the paper how they develop research productivity in their institutions and departments. Table 2 showcases how research is perceived by the teachers in the classroom. It can be inferred from the table that that foreign teachers strongly agreed to all the positive outcomes and impact of research to their professional development, classroom teaching, and promotion of effective teaching and learning. The finding implies that the respondents have beneficial conceptions towards research as an important tool to improve practices, projects, programs, and interventions for the effective delivery system of education. This result is consistent with the previous results of studies that teachers hold positive conceptions on the significant role of research to the teaching practice (Falk \& Blumenreich, 2005; McIntosh, 2010; Halim, Buang, \& Meerah, 2010; McDonough, 2006).

Table 2. Foreign Teachers' Conceptions towards Research

\begin{tabular}{|l|c|c|l|}
\hline \multicolumn{1}{|c|}{ Statement } & $\begin{array}{c}\text { Mean } \\
(\mathbf{n = 6 2})\end{array}$ & S.D. & Interpretation \\
\hline $\begin{array}{l}\text { Doing research is important to the process of teaching and } \\
\text { learning as a teacher. }\end{array}$ & 4.48 & 0.741 & Strongly Agree \\
\hline $\begin{array}{l}\text { Doing research is important to the process of teaching and } \\
\text { learning for the students. }\end{array}$ & 4.42 & 0.780 & Strongly Agree \\
\hline $\begin{array}{l}\text { Doing research provides positive effect to students' learning } \\
\text { and performance. }\end{array}$ & 4.34 & 0.867 & Strongly Agree \\
\hline Doing research develops my skills as professional teacher. & 4.63 & 0.520 & Strongly Agree \\
\hline Doing research makes teachers more abreast to new & 4.58 & 0.588 & Strongly Agree \\
\hline
\end{tabular}


Research Engagement of Foreign Language Teachers among Select Higher Education Institutions in Malaysia

\begin{tabular}{|l|c|c|l|}
\hline knowledge, more systematic and effective. & & & \\
\hline Doing researcher provides solutions to educational problems. & 4.82 & 0.385 & Strongly Agree \\
\hline $\begin{array}{l}\text { Doing research advances knowledge of teachers for classroom } \\
\text { teaching. }\end{array}$ & 4.29 & 0.857 & Strongly Agree \\
\hline Doing research advances my professional career. & 4.45 & 0.739 & Strongly Agree \\
\hline Grand Mean & $\mathbf{4 . 5 0}$ & & $\begin{array}{l}\text { Strongly } \\
\text { Agree }\end{array}$ \\
\hline
\end{tabular}

Legend: Strongly Agree (4.20-5.00); Agree (3.40-4.19); Undecided (2.60-3.39); Disagree (1.80-2.59); Strongly Disagree (1.00-1.79)

An inspection of the data shows that the item obtained the highest mean is doing research provides solutions to educational problems. This finding would explain that foreign teachers were able to see the general essence of research and education. As teachers, they hold the conception that they are the initiators of change by way of doing research they can provide solutions to the emerging problems of education. Burns (2010) asserts that research in education is centred on identification, prioritization, and providing solutions to school and classroom problems which focuses on reflective and transformative teaching practice.

Moreover, the teachers strongly agreed that doing research makes teachers more abreast to new knowledge, more systematic and effective. This means that that as output and outcome of research, it provided teachers better planning skills to effectively and systematically carry out their practices. This finding also entails that the main objective of research is anchored on systematic practice. Hine \& Lavery (2014) concluded that having the professional skills in research is necessary to attain transformative education. Hence, by doing research it simply bridges the gap between the theory and practice where teachers will be able to put themselves in the context. Additionally, Mills (2011a, 2014b) and Stringer (2008) posit that the principle of research is the utilization of systematic process in gaining new insights, initiative changes in the school environment, and improve school effectiveness.

Additionally, the teachers also strongly agreed that doing research develops their skills as professional teacher and advances professional career. They adhere to the belief that being a professional teacher, research skill is one of the embedded attributes they must have. McNiff (2010) states that research is an avenue for professional development by way of reviewing teaching practice and evaluating teaching strategies. This suggests that the respondents consider that being a teacher in the landscape of Education 4.0, they must be able to possess the technical skill to do research. Hence, doing research promotes sense of professional among teachers (Tomlinson, 1995; Brookmyer, 2007; Chevalier \& Buckles, 2019).

Consequently, the foreign teachers manifested a very favourable conception on doing research as important to the process of teaching and learning as a teacher as well as advances knowledge of teachers for classroom teaching. This simply implies that the respondents put high belief that by conducting research they will be able to develop their pedagogical and instructional competence to teach their field of specialization. Previous studies highlighted that research is essential in the effective delivery of content knowledge among teachers because it provided update on pedagogical and instructional competence to address the diverse needs of learners (Ozer, Ritteran \& Wallis, 2010; Furlong \& Sainsbury, 2005; Zhou, 2012; Chen \& Kessler, 2013; Johnson \& Button, 2000).

Finally, the teachers strongly agreed that doing research is important to the process of teaching and learning for the students which provides positive effect to their performance through the 
holistic approaches and strategies generated from research. This eventually implies that in education, upgrading student achievement is an important outcome of research (Clarke \& Fournillier, 2012; Hine, 2013; Johnson, 2012; Mills, 2012).

\section{Qualitative Findings}

The qualitative findings of the study were gathered through Focus Group Discussions (FGDs) and Individual Interviews with the foreign teacher-respondents of selected universities in Malaysia. The findings are thematically analysed and presented in this section. Three emerging themes emerged from the research probes given to the respondents these are: Hindrances to research Engagement and Motivating factors of research engagement. For the purpose of data presentation, respondents were quoted directly. Names and pseudonyms were removed to ensure the ethics.

\section{Hindrances to Research Engagement \\ Lack of Time to Do Research}

The exploration question started with the question on what studies they have conducted in their universities as part of their professional experience. A great deal of the respondents admitted that they have experienced conducting research studies but because of interest of time, they cannot activity engage themselves fully, as one informant revealed: "doing research requires lengthy time, and we are busy in our teaching chores in the University. We are preoccupied with many activities". As seconded by another informed "we understand that research is something laborious to do, and time constraints us to engage ourselves in research since we have heavy teaching loads". In the perspective of another informant, "doing research as part of our teaching hours is impossible since we need to do other equally important tasks in the university as foreign language teachers." It can be thematically captured in the responses that in the view of the respondents, doing research needs time and effort. This construes with Ellis \& Loughland (2016) affirming that lack of time restricted teachers to have meaningful engagement in research. Further corroborated by Vasquez (2017) that a significant reason of teachers' lack engagement in research is the large number of teaching loads given to teachers. The finding on the lack of time as emerging issue among foreign language teachers is an emerging problem among other countries in the world (Kutlay, 2012; Morales, 2016; Borg, 2014; Dehghan \& Srhragard, 2015).

\section{Lack of Research Writing Skills}

Consequently, another challenge which encountered by the respondents in doing research is they lack the research writing skills. Majority of them manifested that they have low level of capacity to write research. An informant affirmed "we find it difficult to engage in research because we are not aware on how to start. We are caught in the dilemma on how we search and evaluate information as starting point of research." The other informant also remarked "doing research requires quantitative and qualitative analysis skills and we find it difficult to identify appropriate method as well as limitations of statistical tools." Another respondent also responded "we are not aware with the rules and guidelines in writing technical report for research. That makes also difficult for us to do research." It can be pragmatically inferred form the responses that the respondents are not yet equipped with research writing skills following the research writing process. Similar research finding has been found in the previous literature (Ynalvez \& Shrum, 2011; Chevalier \& Buckles, 2019; Krell \& Dana, 2012). 


\section{Motivating Factors of Research Engagement}

From the interviews, two motivating factors as sub-themes emerged. Promotion Opportunities and Professional Development. Notwithstanding the challenges and issues postulated by the respondents, they were asked what motivate them to engage in research. The responses are presented and analyzed.

\section{Promotion Opportunity}

The motivating factor which emerged in the interview with respondents on research engagement is career promotion. This shows that career promotion would mean salary increase. They have an understanding the doing research will help them gain higher salary package and other promotion opportunities. One respondent narrated "We actually understand that we will be given promotion opportunities when we do research and published." Another responded "we are motivated to do research because we want to receive higher salary, we do not want to stay in our present rank receiving the same pay". From the glimpse of the responses, the teachers are doing research for financial gains and promotion opportunities. This finding corroborates with the findings of previous literature (Sheikh et al, 2013; Saeed, Kha, Bari \& Khan, 2018; Zuber-Skerritt, 2013; Grima-Farrel, 2017; Hine, 2013)

\section{Professional Development}

In like manner, most of the respondents showed favourable approval on research as a way for enhancing their professional craft in teaching. They admitted that doing research will make them better foreign language teachers. As one quoted "we find research motivating as well as beneficial because it provided us better understanding of our practices making us more effective teachers." Agreeably, one also opined "if we will not engage ourselves to research then we cannot deal with the needs of pedagogical changes in Education 4.0". One further added "we conduct research because we need to provide better opportunities in enhancing student learning." Indeed, in the views of the teachers, they manifest motivation in research engagement because it will give the opportunity to advance their teaching profession. These findings are consistent with the previous findings of scholars (Cain \& Milovic, 2010; Mahani, 2012; Borg \& Burns, 2010; Morales, 2016).

\section{CONCLUSION AND RECOMMENDATION}

This paper ends with the sense that work is an important forum for professional learning for foreign language teachers, a transformative and transforming method for addressing instructional challenges as well as enhancing school effectiveness. This study suggests that foreign language teachers showed a modest degree of research ability while they held positive views on the principles of research as a resource for presenting solutions to educational challenges that transcend the awareness of teachers ' content, pedagogical and instructional abilities, and positive learning outcomes. Moreover, the barriers to international teachers ' participation in research are embodied in the lack of time to do work and lack of science writing skills. Additionally, findings from the qualitative angle revealed that promotional incentive and professional growth are the driving factors for involving international teachers in study.

Study results gave many ramifications for educational administration and implementation in Chinese universities ' foreign-language departments. First, this study not only has significant consequences for Chinese universities, but also for all higher education institutions around the 
world, so it is important to recognize the need for strong university support to maintain efforts by switching from teaching-centered universities to research-impact-outcome universities. It will concentrate on fostering scientific creativity by creating professional, versatile and efficient human capital capable of producing, testing, disseminating, implementing and utilizing new innovations, discoveries and technologies. Second, because international teachers have demonstrated a modest degree of research potential, a long-term professional development program will be established based on the limitations and strengths found in this report, which would also resolve the found research barriers of teachers. The implementation strategy will provide sequence of proactive strategic preparations and review to close the difference between what is and what should be. Furthermore, the Faculty Growth Study Plan will have the following sections and components: (a) capacity-building for international teachers by workshops and writing workshops on study distance identification, research and methodological analysis, survey methodology, research process, professional writing, research publications and dissemination; (b) administrative resee support system;

However, this paper concentrated mainly on the level of study ability of international students, study ideas and perspectives on barriers to their research participation using mixed-method sample methods to limited numbers of respondents. Therefore, the analysis may produce and interpret deeper and differing trends as other variables such as socio-economic profile, cultural context, and interest in teachers ' personality and research subject may forecast research efficacy. Likewise, another analysis can be performed if the work commitment of teachers can be associated with learning outcomes.

\section{REFERENCES}

Alhija, F. M., \& Majdob, A. (2017). Predictors of teacher educators' research productivity. Australian Journal of Teacher Education (Online), 42 (11), 34.

Al-Maamari, F., Al-Aamri, K., Khammash, S., \& Al-Wahaibi, M. (2017). Promoting EFL teacher research engagement through a research support programme. RELC Journal, 48(3), 389-404. Retrieved from https://journals.sagepub.com/doi/abs/10.1177/oo33688216684282

Bai, L. (2018). Language teachers' beliefs about research: A comparative study of English teachers from two tertiary education institutions in China. System, 72, 114-123.

Bai, L., \& Hudson, P. (2011). Understanding Chinese TEFL academics' capacity for research. Journal of Further and Higher Education, 35(3), 391-407.

Biruk, E. H. (2013). The practice and challenges in conducting action research: The case of Sululta Secondary School (Doctoral dissertation, MA Thesis). Retrieved from http://etd. aau. edu. et/bitstream/123456789/4842/1/33.\% 2oBiruk\% 2oHaile. p df (28 December, 2018)). http://etd.aau.edu.et/bitstream/123456789/4842/1/33.\%20Biruk\%2oHaile.pdf

Borg, S. (2014). Teacher research for professional development. In Pickering, G and Gunashekar, P (Eds.), Innovation in English Language Teacher Education. (pp.23-28). Selected papers from the fourth International Teacher Educator Conference Hyderabad, India

Borg, S. (2014). Teacher research for professional development. In G. Pickering \& P. Gunashekar (Eds.), Innovation in English language teacher education (pp.23-28). Selected papers from the fourth International Teacher Educator Conference, Hyderabad, India. https://englishagenda.britishcouncil.org/continuing-professional-development/cpdteachertrainers/innovation-english-language-teacher-education

Borg, S., \& Liu, Y. (2013). Chinese college English teachers' research engagement. Tesol Quarterly, 47(2), 270-299.

Brookmyer, J. (2007). Findings from a survey of the CRESS [3] Teacher Research Program. Windows on our classroom, 12, 123-133 
Burns, A., \& Westmacott, A. (2018). Teacher to researcher: Reflections on a new action research program for university efl teachers. Profile Issues in TeachersProfessional Development, 20(1), 15-23.

Cain, T. (2011). Teachers' classroom-based action research. International Journal of Research $\mathcal{E}$ Method in Education, 34(1), 3-16.

Chen, Y., Nixon, M. R., Gupta, A., \& Hoshower, L. (2010). Research Productivity of Accounting Faculty: An Exploratory Study. American Journal of Business Education, 3(2), 101-115.

Chevalier, J. M., \& Buckles, D. J. (2019). Participatory action research: Theory and methods for engaged inquiry. Routledge.

Chow, K. C. K., Chu, S. K. W., Tavares, N., \& Lee, C. W. Y. (2015). Teachers as Researchers: A Discovery of Their Emerging Role and Impact through a School-University Collaborative Research. Brock Education: A Journal of Educational Research and Practice, 24(2), 20-39. Retrieved from https://files.eric.ed.gov/fulltext/EJ1080o2o.pdf

Clarke, P. A. J., \& Fournillier, J. B. (2012). Action research, [13] pedagogy, and activity theory: Tools facilitating two instructors' interpretations of the professional development of four preservice teachers. Teaching and Teacher Education, 28(5), 649-66o.

Dai, W. D. (2001). On further improving English Language learning in China-Suggestions for consideration. Foreign Languages and Their Teaching, 147(7), 1, 32.

Dehghan, F., \& Sahragard, R. (2015). Iranian EFL teachers' views on action research and its application in their classrooms: A case study. Journal of Teacher Education and Educators, 4(1), 39-52. http://jtee.org/document/issue7/MAKALE\%203.pdf

Ellis, N., \& Loughland, T. (2016). The challenges of practitioner research: A comparative study of Singapore and NSW. Australian Journal of Teacher Education, 41(2), https://doi.org/10.14221/ajte.2016v41n2.8

Falk, B. \& Blumenreich, M. (2005). The power of questions: A guide to teacher and student research. Portsmouth, NH: Heinemann.

Fullan, M. (2013). Stratosphere: Integrating technology, pedagogy, and change knowledge. Pearson Canada.

Furlong*, J., \& Salisbury, J. (2005). Best practice research scholarships: An evaluation. Research papers in education, $20(1), 45-83$.

Furlong, J. \& Salisbury, J. (2005). Best practice research scholarships: An evaluation. Research Papers in Education, 20(1), 45-83. http://dx.doi.org/10.1080/0267152052000341336

Gao, X. (2006). Researching into the research capability development of English language teachers. Education and Management, (4), 48-49.

Grima-Farrell, C. (2017). What Matters in a Research to Practice Cycle?. Springer Singapore: https://doi.org/10.1007/978-981-10-2087-2

Guo, L., Huang, J., \& Zhang, Y. (2019). Education Development in China: Education Return, Quality, and Equity. Sustainability, 11(13), 3750.

Halim, L., Buang, N. A., \& Meerah, T. S. (2010). Action research as instructional supervision: Impact on the professional development of university based supervisors and science student teachers. Procedia-Social and Behavioral Sciences, 2(2), 2868-2871.

Hine, G., \& Lavery, S. D. (2014). Action research: Informing professional practice within schools. Issues in Educational Research, 24(2) 162-173. http://www.iier.org.au/iier24/hine.html

Hine, S. C. \& Lavery, S. (2014). Action research: Informing professional practice within schools. Issues in Educational Research, 24(2), 162-173. http://www.iier.org.au/iier24/hine.html

https://doi.org/10.1080/1743727X.2011.552307

Huang. J.B. (2006). TEFL academics and research. English Knowledge, (6), 1-2, 7.

Johnson, M. J. \& Button, K. (2000). Connecting graduate education in language arts with teaching contexts: The power of action research. English Education, 32(2), 107-126. http://www.ncte.org/journals/ee/issues/v32-2

Jöns, H., \& Hoyler, M. (2013). Global geographies of higher education: The perspective of world university rankings. Geoforum, 46, 45-59.

Keuk, C. N. (2015). Investigating communities of practice and ELT teacher research in Cambodia.

Kiatkheeree, P. (2014). The research culture in an English as a foreign language Thailand university context: a thesis presented in partial fulfilment of the requirements for the degree of Doctor of Philosophy in 
Education at Massey University, Palmerston North, New Zealand (Doctoral dissertation, Massey University).

Krell, D. E., \& Dana, N. F. (2012). Facilitating action research: a study of coaches, their experiences, and their reflections on leading teachers in the process of practitioner inquiry. Professional development in education, $38(5), 827-844$.

Kutlay, N. (2012). A survey of English language teachers' views of research. Procedia - Social and Behavioral Sciences. 70, 188-206. https://doi.org/10.1016/j.sbspro.2013.01.055

Larsen, P., \& Von Ins, M. (2010). The rate of growth in scientific publication and the decline in coverage provided by Science Citation Index. Scientometrics, 84(3), 575-603.

Liu, Y., \& Borg, S. (2014). Tensions in teachers' conceptions of research: Insights from college English teaching in China. Chinese Journal of Applied Linguistics, 37(3), 273-291.

Lopatina, O. V., Borisov, A. M., Leyfa, I. I., Galimzyanova, I. I., Yatsevich, L. P., Demyanenko, M. A., \& Masalimova, A. R. (2015). Role of foreign language teacher shaping students' research skills. Asian Social Science, 11(4), 135.

Luole, Z., \& Baoqi, Z. (2011). Teaching practices of foreign teachers of English in China and students' responses. Retrieved from http://litu.tu.ac.th/FLLT2013/www.fllt2013.org/private_folder/Proceeding/537.pdf

Mahani, S. (2012). Enhancing the quality of teaching and learning through action research. Journal of College Teaching \& Learning, 9(3), 209-215. https://doi.org/10.19030/tlc.v9i3.7086

McDonough, K. (2006). Action research and the professional development of graduate teaching assistants. The Modern Language Journal, 9o(1), 33-47. http://dx.doi.org/10.1111/j.1540-4781.2006.00383.x

McIntosh, P. (2010). Action research and reflective practice: Creative and visual methods to facilitate reflection and learning. Routledge.

McNiff, J. (2010). Action research for professional development: Concise advice for new and experienced action researchers. Dorset: September Books

Meerah, T. S. M., Osman, K., Zakaria, E., Ikhsan, Z. H., Krish, P., Lian, D. K. C., \& Mahmod, D. (2012). Developing an instrument to measure research skills. Procedia-Social and Behavioral Sciences, 6o, 63o636.

Mehrani, M. B. (2015). English Teachers' Research Engagement: Level of Engagement and Motivation. Iranian Journal of Language Teaching Research, 3(1), 83-97. Retrieved from https://files.eric.ed.gov/fulltext/EJ1127337.pdf

Mehrani, M. B. (2015). English Teachers' Research Engagement: Level of Engagement and Motivation. Iranian Journal of Language Teaching Research, 3(1), 83-97. Retrieved from https://www.researchgate.net/publication/305392083_English_Teachers'_Research_Engagement_Curre nt_Barriers_and_Future_Strategies/link/578cb7obo8ae59aa66813467/download

Mehrani, M., \& Behzadnia, A. (2013). English teachers' research engagement: Current barriers and future strategies. International Journal of Foreign Language Teaching and research, 1(4), 19-33. Retrieved from file://C:/Users/KTM/Downloads/EnglishTeachersResearchEngagementCurrentBarriersandFutureStrat egies.pdf

Mills, G. E. (2011). Action Research: A guide for the teacher researcher (4th ed.). Boston: Pearson.

Mills, G. E. (2014). Action Research: A guide for the teacher researcher (5th ed.). Boston: Pearson

Ministry of Education. (2007). 1990 nian yi lai gao xiao he bing qing kuang (jie zhi 2005 nian 5 yue 26 ri) [The institutes of higher learning amalgamated since 1990 (up to May 26, 2005)]. http://www.moe.gov.cn/edoas/website18/info25506.htm

Morales, M. P. E. (2016). Participatory action research (PAR) cum action research (AR) in teacher professional development: A ' review. International Journal of Research in Education and Science, 2(1), 156-165. Retrieved from https://files.eric.ed.gov/fulltext/EJ1105165.pdf

Norasmah, O., \& Chia, S. Y. (2016). The challenges of action research implementation in Malaysian schools. Pertanika Journal of Social Science and Humanities, 24(1), 43-52.

Ozer, E. J., Ritterman, M. L., \& Wanis, M. G. (2010). Participatory action research (PAR) in middle school: Opportunities, constraints, and key processes. American journal of community psychology, 46(1-2), 152166. 
Reyes-Cruz, M. D. R., Murrieta-Loyo, G., \& Perales-Escudero, M. D. (2018). Foreign Language Faculty Research-Related Beliefs, Perceptions, and Research Motivation at Three Mexican Universities. Profile Issues in TeachersProfessional Development, 20(2), 35-49.

Saeed, I., Khan, N. F., Bari, A., \& Khan, R. A. (2018). Factors contributing to the lack of interest in research activities among postgraduate medical students. Pakistan journal of medical sciences, 34(4), 913.

Schoonenboom, J., \& Johnson, R. B. (2017). How to construct a mixed methods research design. KZfSS Kölner Zeitschrift für Soziologie und Sozialpsychologie, 69(2), 107-131.

Shariatmadari, M., \& Mahdi, S. (2012). Barriers to research productivity in Islamic Azad University: Exploring faculty members' perception. Indian Journal of Science and Technology, 5(5), 2765- 2769.

Sheikh, A. S. F., Sheikh, S. A., Kaleem, A., \& Waqas, A. (2013). Factors contributing to lack of interest in research among medical students. Advances in medical education and practice, 4, 237. https://doi.org/10.2147/AMEP.S51536

Shen, B. (2017). Factors Affecting Research Engagement of Foreign Language Teachers in China, European Journal of Hospitality and Tourism Research, Vol.5, No.1, pp.24-30, April 2017. Retrieved from http://www.eajournals.org/wp-content/uploads/Factors-Affecting-Research-Engagement-of-ForeignLanguage-Teachers-in-China.pdf

Stringer, E. T. (2008). Action research in education (2nd ed.). New Jersey: Pearson.

Tomlinson, C.A. (1995). Action research and practical inquiry: An overview and an invitation to teachers of gifted learners. Journal for the Education of the Gifted, 18(4), 468-484.

Ulla, M. B. (2017). Teacher Training in Myanmar: Teachers' Perceptions and Implications. International Journal of Instruction, 10(2), 103-118. http://www.eiji.net/dosyalar/iji_2017_2_7.pdf https://doi.org/10.12973/iji.2017.1027a

Vásquez, V.E.L. (2017). Teachers as researchers: Advantages, disadvantages and challenges for teachers intending to engage in research activities. Retrieved from https://www.academia.edu/719736 on January 15, 2017.

Vec, T. R. \& Rupar, B. (2015). Evaluation of teachers' perceptions of action research process effects: What leadership style is appropriate for the implementation of change in schools? National Education Institute, Slovenia. http://www.esri.mmu.ac.uk/carnnew/studydays/2008/glasgow/CARN_NEI_Slovenia.pdf

$\mathrm{Xu}, \mathrm{Y}$. (2014). Becoming researchers: A narrative study of Chinese university EFL teachers' research practice and their professional identity construction. Language Teaching Research, 18(2), 242-259.

Yang, Z., Zhang, S. J. and Xie, J. W. (2001). An analysis of current situation and problems of TEFL academics' research performance. Foreign Language Education, 22(6), 79-83.

Ynalvez, M. A., \& Shrum, W. M. (2011). Professional networks, scientific collaboration, and publication productivity in resource-constrained research institutions in a developing country. Research Policy, 40(2), 204-216.

Zhang, W., Xu, X., Evans, R., \& Yang, F. (2018). Towards internationalization: a critical assessment of China's public administration research in a global context 2000-2014. International Public Management Journal, 21(1), 74-104.

Zhou, Luole, and Zhang Baoqi. (2013) Teaching Practices of Foreign Teachers of English in China and Students' Responses. FLLT Conference Proceedings by LITU. Retrieved from http://www.litu.tu.ac.th/journal/

Zuber-Skerritt, O. (2013). Professional development in higher education: A theoretical framework for action research. Routledge. 